nience, what offices are in the habit of recognising our just claims for remuneration.

I would strongly advise all my professional brethren who consider they are entitled to a fee for such services, to remember the titles of those offices, and in a very short time every office in the kingdom would find it to be not only its interest, but absolutely essential to its existence, to make a suitable return for the opinions of medical men, which they are so ready to make use of, and without which they cannot venture to grant a single policy.

$$
\begin{aligned}
& \text { I am, Sir, your obedient servant, } \\
& \text { Eover, August 20, 1848. }
\end{aligned}
$$

\section{THE UPTON.ON-SEVERN UNION.} To the Editor of The Lancet.

SrR,-It has been with no small degree of pain that I have for the last few weeks read the correspondence published by the Upton-on-Severn surgeons; for it appears to me, that the great bearing of the case on the profession generally is being, and indeed is already, laid aside; and instead of its being a public, it becomes a private case, between the late and the present medical officers of the union. Surely, would it not have been more proper to have put Mr. West's case, as showing the impropriety of his taking the Powick district, on the score of not letting the guardians feel the want of a medical officer, than of placing it on the more private and personal ground that Mr. Braddon lias done in your number for the 2nd of September?

No one can for an instant sympathize with Mr. West. The part he has played has indeed been unworthy a medical man,- to give in to the wishes of his influential friends, and accept the appointment, thereby doubtless improving his private influence and practice, but most decidedly not his standing in the eyes of the profession; for even if he did not approve of the proceedings of the late officers, surely he did not intend to record his approval of the principle of the present system of poor-law medical relief, which he undoubtedly tacitly did, by helping the guardians out of their difficulty. On such an occasion, should he not have borne in mind the system, rather, at which the blow was struck, than the individuals who struck it ?

It would be fruitless here to expatiate on the so-often urged point of medical men, as a body, being always foiled in their attempts by want of unanimity, than which a more striking instance than the present can scarcely be found. But most assuredly, so long as guardians find that medical mer squabble amongst themselves, and so long as they can find men so anxious to accept the enviable position of union doctor as Mr. Marsh seems to find it,- or men as Mr. West to accept office, even for a day, - while brother professionals make a strike against a system that even Messrs. West and Marsh must acknowledge to be degrading, - so long will neither members of Parliament, guardians, or the public, acknowledge or try to mitigate the humilating position of the poor-law medical officer.-I am, Sir, yours very obediently,

September 4 th, 1848.

Junius.

\section{POOR LAW MIEDICAL RELIEF.-THE BICESTER UNION.}

To the Editor of The Lancet.

SIR,-Your question "Of what use are Poor Law Committees and Conventions "? in rour leading article of the 5th inst., induces me to give an opinion formed upon strict observation of matters cunnected with the present mode of administering medical relief to the poor, and the system resorted to, to procure such relief, by those to whose care the whole pauper population is entrusted. That opinion is, they are totally useless - unless, by the exposures they are indncing, and likely to induce, they may be the means of having the whole fabric of medical relief to the poor reconstructed, and upon a broader basis. Pressure from without is reyuisite; and with two or three good men in the cause, perpetually dinging the dirge into the Minister's cars, he must at length awake from the state of lethargy or apathy in which, as relates to general as well as medical reform, he has long indulged. Finality finds few friends, and must succumb to oux transatlantic brethren's "go a-head" system.

Until a change is made by which each pauper can seek for medical relief from the person he believes likely to relieve him, or is nearest his residence, and until medical men are better remunerated for their toil and time, the sick pauper will not have that attendance that he justly deserves, and humanity points to
With the existing law, until there is a greater esprit de corps among members of the medical profession, which is at present at a discount, the powers that be will have no diffculty in carrying out their Malthusian plan. For instance, in this, the Biccster Union, a highly respected medical officer was arraigned for neglect of duty. The case was formally discussed before an Assistant Poor Law Commissioner and full board of guardians. It was so evident that there was no wilful neglect, that twenty-five out of twenty-seven of the guardians voted in his favour; yet he was dismissed by the irresponsible despots, and by them the board was ordered to electanother in his place. The espritde corps ruling high in the neighbourhood, none of his medical brothers would accept the office, and a person was of necessity elected, which same individual was considered by the same commissioners as incapable of holding the office, after being elected in an adjacent union, for want of qualification! The man incompetent to attend the paupers in one union is quite competent in tho next-O tempora! 0 mores! You say, "If there had been no qualified," \&c. Qualification, as illustrated above, is no obstacle. Get money-honestly if you can; but get money - is said to have been the advice of the Scotch parent to the afterwards celebrated Scotch phy sician. So the poor law commissioners say to the Upton guardians-"Get a medical man, qualified if you can; but so long as he is a medical man, do not look at acquirements, capability, or qualification-but get a medical man."

Alter the law as regards administration of relief to the sick poor; appoint medical inspectors, deputies, and their acting co-equals; and the rate-payers would not suffer more in pocket-the poor, in person, not half so much.

August 24, 1848. Your obedient servant, Amicus Pauperum

\section{To the Editor of The LaNCET.}

SIR,-I have been very much gratified to observe that the views I propounded in a letter inserted in Tre Lancer of March 18, for what you were pleased to call an equitable adjustment of the question of medical attendance on the poor, have met with several supporters, and more particularly Dr. J. Davies of Coleshill, Warwickshire, who has advocated precisely the same plan, in an excellent paper inserted in THE LAXCET of this week. Dr.J. Davies says his system is intended to apply to the rural districts, and confesses himself incapable of forming an opinion how far it might be advisable to extend it to large manufacturing towns. Now $T$ have not the least doubt of its being applicable to all districts, either in country or town. It is notorious that the present system of poor-law medical relief is characterized by eruelty, both to the profession and the poor-the union medical officer being very ill-paid, and the poor, in numerous instances, shamefully neglected. In order to render it satisfactory alike to the poor and the profession, by far the simplest and best system would be, to throw open the poor-law medical attendance to every qualified member of the profession, so as to give the poor an opportunity of selecting any surgeon in the district they thought proper, and it must be apparent to every thinking mind, that they would be much better attended to-at the same time, medical men must be better remunerated. Such a plan appears, on the face of it, so very fair and efficacious, that $I$ cannot conceive it would be opposed, except by some flinty-hearted guardian, on the score of a little extra expense or some surgeon who has made his medical attendance-under the poor-law, on the elder branches of a family, the means of compelling the younger branches to employ him.

August 26, 1848

I am, Sir, your obedient servant,

Humanitas.

\section{DISEASES OF THE SPINAL SYSTEM.} To the Editor of The Lancer

Sir,-Dr. Marshall Hall, at page 205 of The Laxcet for August 19th, remarks - "no experiment has been devised, to my knowledge, to induce aurmented susceptibility of the spinal system, through the medium of the incident nerve or nerves of any part of the spinal system." I may understand him incorrectly, but it does seem to me that his ideas lead him to believe that lesion of an incident nerve is always or at any time a cause of tetanus; - that is to say, that augmented susceptibility may commence in a wounded nerve, and being conveyed to a centre, may create, not excite, tetanus. I may be presumptuous in seeking for a remark or two from him on the subject, but my excuse must be that I have recently hnown a fatal case of tetanus occur, to which, had I been called, I should have recommended the " perfect quietude" treatment with much hopeful confidence. 